\title{
Non-invasive ventilation and surfactant treatment as the primary mode of respiratory support in surfactant-deficient newborn piglets
}

\author{
Carmen Rey-Santano ${ }^{1,5}$, Victoria E Mielgo ${ }^{1,5}$, Miguel Angel Gomez-Solaetxe ${ }^{2}$, Francesca Ricci ${ }^{3}$, Federico Bianco ${ }^{3}$, \\ Fabrizio Salomone ${ }^{3}$, Begoña Loureiro ${ }^{4}$ and Jon López de Heredia y Goya ${ }^{4}$
}

BACKGROUND: Nasal continuous positive airway pressure (NCPAP) and nasal intermittent positive pressure ventilation (NIPPV), forms of non-invasive ventilation (NIV) for respiratory support, are increasingly being chosen as the initial treatment for neonates with surfactant (SF) deficiency. Our objective was to compare NCPAP with NIPPV with or without SF administration as a primary mode of ventilation.

METHODS: Twenty-four newborn piglets with SF-deficient lung injury produced by repetitive bronchoalveolar lavages were randomly assigned to NCPAP or NIPPV, with or without SF administration (InSurE method). We evaluated pulmonary, systemic (hemodynamic and oxygen metabolism), and cerebral effects.

RESULTS: SF-deficient piglets developed respiratory distress $\left(F_{\mathrm{iO} 2}: 1, \quad \mathrm{pH}<7.2, \quad P_{\mathrm{aCO} 2}>70 \mathrm{~mm} \mathrm{Hg}, \quad P_{\mathrm{aO} 2}<70 \mathrm{~mm} \mathrm{Hg}\right.$, and $C_{\text {dyn }}<0.5 \mathrm{ml} / \mathrm{cmH}_{2} \mathrm{O} / \mathrm{kg}$ ). Gradual improvements in pulmonary status were observed in both NIV groups, with NIPPV achieving lower lung inflammation markers and injury scores. Both SF-treated groups obtained significantly better respiratory outcomes than groups not treated with SF before NIV. All NIV-treated groups showed low brain injury scores.

CONCLUSION: In spontaneously breathing SF-deficient newborn piglets, NIPPV is a suitable NIV strategy. SF administration in combination with NCPAP or NIPPV improves pulmonary status providing extra protection against pulmonary injury. No injury to the developing brain was observed to be associated with these NIV strategies, with or without SF therapy.

$\mathbf{N}$ asal continuous positive airway pressure (NCPAP) and nasal intermittent positive pressure ventilation (NIPPV) are two widely used ways of providing non-invasive ventilation (NIV) in intensive care units. The use of NIV is increasingly gaining acceptance as a primary mode of respiratory support in spontaneously breathing preterm infants with respiratory distress syndrome (RDS) and in infants with hypoxemic and hypercarbic respiratory failure, in order to avoid ventilator-induced lung injury $(1,2)$.

NCPAP provides continuous positive pressure with the basic goal of achieving distension of the lungs, thereby preventing collapse of the alveoli during expiration. NIPPV is the augmentation of NCPAP with superimposed ventilator breaths at a set peak pressure, which includes the advantages of NCPAP treatment with less work of breathing (3). These strategies may minimize lung inflammation and subsequent acute and chronic injury associated with mechanical ventilation. Although the use of NIPPV as a primary mode of respiratory support has been described to decrease the need for mechanical ventilation, reduce the rate of extubation failure, and decrease the need for re-intubation and apneas rates compared with results with NCPAP, differences between the NIV strategies have not been consistent across studies (4-9). On the other hand, for some preterm babies, NIV alone does not offer sufficient ventilator support to attain adequate ventilation, and related increases in mortality or morbidity due to the absence or delay in surfactant (SF) administration have been described (10).

To date, a relatively small number of preclinical and clinical studies have assessed the lung impact of different modalities of NIV (9,11-13). To our knowledge, no studies have been designed to compare the physiological and pathological effects of NCPAP and NIPPV, with and without SF administration, when used as the primary mode of ventilation.

In this context of uncertainty of what is the best NIV strategy, the hypothesis of the study was to demonstrate that NIPPV may potentially be more efficient and safe than NCPAP, although the SF administration given shortly before either NIV strategy would have synergistic effect in the improvement of the respiratory outcomes, without brain injury. Our primary objective was to compare these modes of NIV (NCPAP vs. NIPPV) with and without SF administration, evaluating their impact on gas exchange, hemodynamic parameters, oxygen metabolism, and lung injury score in

\footnotetext{
${ }^{1}$ Animal Research Unit, BioCruces Health Research Institute, Barakaldo, Bizkaia, Spain; ${ }^{2}$ Medical Devices Group, University of Basque Country, Portugalete, Bizkaia, Spain; ${ }^{3}$ Chiesi Farmaceutici, R\&D Department, Parma, Italy; ${ }^{4}$ Neonatal Intensive Care Unit, Cruces University Hospital, Barakaldo, Bizkaia, Spain. Correspondence: Carmen Rey-Santano (macarmen.reysantano@osakidetza.eus)

${ }^{5}$ These authors contributed equally to this work.

Received 20 October 2017; accepted 24 December 2017; advance online publication 14 February 2018. doi:10.1038/pr.2018.5
} 


\section{NIV and surfactant for RDS treatment 1 Articles}

spontaneously breathing SF-deficient newborn piglets. A secondary objective was to evaluate the effect of these ventilation strategies on the brain development, this point not being well studied previously.

\section{METHODS}

\section{Animal Preparation}

The experimental protocol meets European and Spanish regulations for the protection of experimental animals (UE2010/63 and RD5312013) and was approved by the Ethic Committee for Animal Welfare of Cruces University Hospital-BioCruces Health Research Institute.

First, 2- to 4-day-old newborn piglets (hybrid F1: of Large White $\mathrm{x}$ Landrace, gestation period of 115 days) were sedated with an intramuscular (i.m.) ketamine (15 mg/kg)-diazepam $(2 \mathrm{mg} / \mathrm{kg})$ atropine $(0.05 \mathrm{mg} / \mathrm{kg})$ injection and anesthetized with sevofluorane $(2-3 \%)$. A cuffed-tracheal tube was inserted and connected to positive pressure ventilator (VIP Bird, Bird Products, Palm Springs, CA) with the following initial settings: $F_{\mathrm{iO} 2}=0.21-0.28$, respiratory frequency $\left(f_{R}\right)=20$ breaths $/ \mathrm{min}$, positive end expiratory pressure $=3 \mathrm{cmH}_{2} \mathrm{O}$ and positive-inspiratory pressure $=9$ $11 \mathrm{cmH}_{2} \mathrm{O}$.

An arterial catheter was inserted into the femoral artery to monitor mean arterial blood pressure (MABP) and heart rate (HR) and to obtain blood samples for gas analysis. In addition, a 5Fr three-lumen catheter was inserted into the jugular vein for fluid maintenance $(5 \mathrm{ml} / \mathrm{kg} / \mathrm{h})$ and obtaining venous blood samples.

The right common carotid blood flow was measured with an ultrasonic flow probe (Transonic Systems, Ithaca, NY), as a proxy for cerebral blood flow. Rectal temperature was maintained between 38 and $39^{\circ} \mathrm{C}$ with heating lamps.

\section{Lung Injury and Study Design}

SF-deficient lung injury was achieved by repetitive saline lavage $\left(30 \mathrm{ml} / \mathrm{kg} ; 37^{\circ} \mathrm{C}\right.$ with $\left.F_{\mathrm{iO} 2}: 1\right)(14,15)$. After the first bronchoalveolar lavage (BAL), the positive end expiratory pressure was increased to $5 \mathrm{cmH}_{2} \mathrm{O}$, and positive-inspiratory pressure and $\mathrm{f}_{\mathrm{R}}$ were adjusted to a maximum of $25 \mathrm{cmH}_{2} \mathrm{O}$ and $45 \mathrm{bpm}$, respectively. Lavage procedures were repeated at 5 min intervals until $P_{\mathrm{aO} 2}<100 \mathrm{~mm} \mathrm{Hg}$ was obtained. After $30 \mathrm{~min}$ of stabilization, all newborn piglets received a bolus dose of $20 \mathrm{mg} / \mathrm{kg}$ of caffeine citrate (Peyona $20 \mathrm{mg} / \mathrm{ml}$; Chiesi Farmaceutici, Parma, Italy) before extubation. Customized tightly fitting short binasal prongs were placed in all animals. Once spontaneous breathing was established, piglets were randomly assigned to one of the following groups:

NCPAP group $(n=6)$ : newborn piglets with SF-deficient lung injury were maintained on NCPAP for $180 \mathrm{~min}$, without SF treatment.

NCPAP-InSurE group $(n=6)$ : newborn piglets with SF-deficient lung injury received $200 \mathrm{mg} / \mathrm{kg}$ of SF (Curosurf, Chiesi Farmaceutici) using the InSurE method (16), and were maintained on NCPAP for $180 \mathrm{~min}$.

NIPPV group $(n=6)$ : newborn piglets with SF-deficient lung injury were maintained on NIPPV for $180 \mathrm{~min}$, without SF treatment.

NIPPV-InSurE group $(n=6)$ : newborn piglets with SF-deficient lung injury received $200 \mathrm{mg} / \mathrm{kg}$ of SF (Curosurf), using the InSurE method (16), and were maintained on NIPPV for $180 \mathrm{~min}$.

The level of NCPAP was set at $5 \mathrm{cmH}_{2} \mathrm{O}$ with a flow of $6.5 \mathrm{l} / \mathrm{min}$. Alternatively, NIPPV was established with the following rescue parameters: $\mathrm{f}_{\mathrm{R}}$ of $40 \mathrm{bpm}$; positive end expiratory pressure $5 \mathrm{cmH}_{2} \mathrm{O}$; and positive-inspiratory pressure $15-17 \mathrm{cmH}_{2} \mathrm{O}$.

\section{Physiological Measurements}

All physiological parameters were obtained at baseline (basal values), after the BAL procedure, during the first $30 \mathrm{~min}$ after $\mathrm{BAL}$ (stabilization period) under conventional mechanical ventilation (30 min of stabilization) and, after extubation, during NCPAP or NIPPV every $30 \mathrm{~min}$ until the end of experiment, at $180 \mathrm{~min}$.

- Arterial $\mathrm{pH}, P_{\mathrm{aO} 2}, P_{\mathrm{aCO} 2}$ and base excess, lactic acid, glucose were measured.

- Hemodynamic parameters: HR, MABP, and carotid blood flow were measured and recorded.

- Oxygen metabolism and intrapulmonary shunt: arterialoxygen-content $\left(\mathrm{C}_{\mathrm{aO} 2}\right)$, oxygen delivery $(\mathrm{OD})$, oxygen consumption $\left(\mathrm{V}_{\mathrm{O} 2}\right)$, and intrapulmonary-shunt (Qs/Qt) were calculated.

- Lung mechanics were measured with a computerized system (M1014A, Philips Medical System, Eindhoven, The Netherlands). The analyzer reported values for dynamic compliance $\left(C_{\mathrm{dyn}}\right)$, tidal volume, and airway resistance at baseline, after the BAL procedure, after $30 \mathrm{~min}$ of stabilization (ST), and at the end of the experiment (animals were intubated and lung mechanics were measured).

\section{Lung Tissue Analysis}

During postmortem, the lungs were removed and perfused with saline. The left lung was isolated, occluded, placed into liquid nitrogen, and stored at $-80^{\circ} \mathrm{C}$ until use for biochemical analysis, whereas the right lung was fixed in $4 \%$ formalin at $15 \mathrm{cmH}_{2} \mathrm{O}$ for histological analysis.

In frozen lung samples interleukin (IL)-8, IL-1B, and tumor necrosis factor- $\alpha$ concentrations were measured using specific ELISA kits for porcine interleukins (Abnova, Tapei City, Taiwan). Finally, protein concentrations were determined by the Bradford method (Bio-Rad, Hercules, CA) (17). Furthermore, slides from each $5-\mu \mathrm{m}$ section were stained with hematoxylin-eosin and analyzed with light microscopy. Lung injury was scored by a pathologist blinded to treatment group using a semiquantitative scoring system. Pathological signs of lung injury (atelectasis, alveolar and interstitial inflammation, alveolar and interstitial hemorrhage, edema, and necrosis) were each scored on a $0-4$ point scale: 0 corresponding to no injury; 1,2 , and 3 to injury to 25,50 , and $75 \%$ of the field, respectively; and 4 to injury across the field (18).

\section{Brain Tissue Analysis}

To perform histological analysis, the brain was fixed (4\% formalin) and divided into cortex, inner regions (striatum, thalamus, and hippocampus), cerebellum, and brain stem. A total of 20 fields were analyzed with light microscopy. Pathological features of brain injury (necrosis, inflammation, hemorrhage, edema, and infarction) were each scored on a 0 - to 3 -point scale: 0 corresponding to no injury; and 1,2 , and 3 to injury to mild, moderate, and severe injury across the field. The presence of more than five necrotic cells/field was considered to indicate neuronal necrosis (score range: 0-20) (19).

\section{Statistical Analysis}

Values are expressed as mean \pm SEM. Results were assessed using the Levene's test to confirm the homogeneity of variance between the different treatments and the Kolmogorov-Smirnoff test for normality (JMP8, Statistical Discovery, SAS, NC). Results (gas exchange, hemodynamic parameters, oxygen metabolism, and lung mechanics) were analyzed using one- and two-way ANOVA as a function of group and time for repeated measures. Lung biochemical and injury score and brain injury score were analyzed using nonparametric Wilcoxon test. A $P$ value of $<0.05$ was considered significant.

\section{RESULTS}

Twenty-four newborn piglets from different litters age $4 \pm 1$ days and weighing $2.0 \pm 0.1 \mathrm{~kg}$ were similar in size and in age. Multiple BALs (average of 11-15 BALs) were needed to induce the lung injury, no significant differences being 
Table 1. Gas exchange and oxygen metabolism in surfactant-deficient newborn piglets treated with non-invasive ventilation (NCPAP or NIPPV) with or without surfactant treatment, using the Insure method

\begin{tabular}{|c|c|c|c|c|c|c|c|c|c|c|c|}
\hline & Groups & Basal & BAL & $30 \mathrm{ST}$ & $15 \mathrm{~min}$ & $30 \mathrm{~min}$ & $60 \mathrm{~min}$ & $90 \mathrm{~min}$ & $120 \mathrm{~min}$ & $150 \mathrm{~min}$ & $180 \mathrm{~min}$ \\
\hline \multirow[t]{4}{*}{$\mathrm{pH}$} & NCPAP & $7.37 \pm 0.02$ & $7.12 \pm 0.03^{\S}$ & $7.18 \pm 0.03^{\S}$ & $7.27 \pm 0.03$ & $7.32 \pm 0.03$ & $7.36 \pm 0.02$ & $7.43 \pm 0.01$ & $7.43 \pm 0.01$ & $7.43 \pm 0.02$ & $7.42 \pm 0.02$ \\
\hline & NIPPV & $7.43 \pm 0.03$ & $7.16 \pm 0.03^{\S}$ & $7.14 \pm 0.04^{\S}$ & $7.07 \pm 0.06^{*}$ & $7.13 \pm 0.15^{*}$ & $7.25 \pm 0.05$ & $7.36 \pm 0.02^{*}$ & $7.39 \pm 0.02^{*}$ & $7.38 \pm 0.02$ & $7.39 \pm 0.02^{* *}$ \\
\hline & $\begin{array}{l}\text { NCPAP- } \\
\text { InSurE }\end{array}$ & $7.36 \pm 0.02$ & $7.19 \pm 0.03^{\S}$ & $7.21 \pm 0.03^{\S}$ & $7.30 \pm 0.04$ & $7.37 \pm 0.02$ & $7.43 \pm 0.01^{*}$ & $7.44 \pm 0.02$ & $7.44 \pm 0.01$ & $7.46 \pm 0.02$ & $7.47 \pm 0.02^{*}$ \\
\hline & $\begin{array}{l}\text { NIPPV- } \\
\text { InSurE }\end{array}$ & $7.36 \pm 0.02$ & $7.13 \pm 0.02^{\S}$ & $7.11 \pm 0.03^{\S}$ & $7.24 \pm 0.03^{\dagger}$ & $7.34 \pm 0.03^{\dagger}$ & $7.41 \pm 0.01^{\dagger}$ & $7.45 \pm 0.01^{\dagger}$ & $7.46 \pm 0.02^{\dagger}$ & $7.47 \pm 0.02^{\dagger}$ & $7.47 \pm 0.02^{\dagger, \pm}$ \\
\hline \multirow{4}{*}{$\begin{array}{l}P_{\mathrm{acO} 2} \\
(\mathrm{~mm} \mathrm{Hg})\end{array}$} & NCPAP & $41 \pm 3$ & $78 \pm 5^{\S}$ & $68 \pm 5^{\S}$ & $62 \pm 8$ & $53 \pm 5$ & $47 \pm 3$ & $40 \pm 3$ & $39 \pm 2$ & $38 \pm 4$ & $38 \pm 4$ \\
\hline & NIPPV & $40 \pm 3$ & $86 \pm 8^{\S}$ & $89 \pm 9^{\S}$ & $110 \pm 10^{*}$ & $99 \pm 12^{*}$ & $78 \pm 8^{*}$ & $58 \pm 2^{*}$ & $55 \pm 2^{*}$ & $56 \pm 3^{*}$ & $54 \pm 3^{*, * *}$ \\
\hline & $\begin{array}{l}\text { NCPAP- } \\
\text { InSurE }\end{array}$ & $41 \pm 3$ & $65 \pm 6^{\S}$ & $68 \pm 4^{\S}$ & $62 \pm 9$ & $50 \pm 5$ & $43 \pm 3$ & $41 \pm 3$ & $39 \pm 2$ & $37 \pm 2$ & $38 \pm 2$ \\
\hline & $\begin{array}{l}\text { NIPPV- } \\
\text { InSurE }\end{array}$ & $39 \pm 3$ & $85 \pm 8^{\S}$ & $77 \pm 6^{\S}$ & $76 \pm 10^{\dagger}$ & $60 \pm 7^{\dagger}$ & $47 \pm 6^{\dagger}$ & $43 \pm 3^{\dagger}$ & $43 \pm 4^{\dagger}$ & $42 \pm 4^{\dagger}$ & $42 \pm 4^{\dagger, t}$ \\
\hline \multirow{4}{*}{$\begin{array}{l}\mathrm{OD}(\mathrm{ml} / \\
\mathrm{min})\end{array}$} & NCPAP & $74 \pm 4$ & $70 \pm 13$ & $74 \pm 9$ & $87 \pm 8$ & $104 \pm 11$ & $84 \pm 6$ & $67 \pm 14$ & $75 \pm 3$ & $78 \pm 5$ & $84 \pm 6$ \\
\hline & NIPPV & $61 \pm 6$ & $58 \pm 7$ & $87 \pm 8$ & $70 \pm 8$ & $77 \pm 5$ & $100 \pm 8$ & $93 \pm 6$ & $87 \pm 9$ & $90 \pm 8$ & $87 \pm 10$ \\
\hline & $\begin{array}{l}\text { NCPAP- } \\
\text { InSurE }\end{array}$ & $68 \pm 8$ & $58 \pm 7$ & $71 \pm 7$ & $83 \pm 9$ & $85 \pm 10$ & $94 \pm 11$ & $94 \pm 12$ & $86 \pm 12$ & $92 \pm 12$ & $95 \pm 6^{* *}$ \\
\hline & $\begin{array}{l}\text { NIPPV- } \\
\text { InSurE }\end{array}$ & $62 \pm 6$ & $48 \pm 5$ & $70 \pm 6$ & $84 \pm 7$ & $97 \pm 5$ & $98 \pm 4$ & $88 \pm 5$ & $89 \pm 3$ & $92 \pm 4$ & $85 \pm 2$ \\
\hline \multirow{4}{*}{$\begin{array}{l}\mathrm{VO}_{2}(\mathrm{ml} / \\
\mathrm{min})\end{array}$} & NCPAP & $16 \pm 2$ & $13 \pm 3$ & $15 \pm 2$ & $10 \pm 4$ & $15 \pm 2$ & $15 \pm 4$ & $12 \pm 2$ & $12 \pm 4$ & $14 \pm 3$ & $16 \pm 2$ \\
\hline & NIPPV & $11 \pm 2$ & $12 \pm 2$ & $11 \pm 3$ & $10 \pm 2$ & $12 \pm 2$ & $13 \pm 1$ & $13 \pm 3$ & $13 \pm 2$ & $14 \pm 2$ & $14 \pm 3$ \\
\hline & $\begin{array}{l}\text { NCPAP- } \\
\text { InSurE }\end{array}$ & $12 \pm$ & $12 \pm 1$ & $13 \pm 3$ & $13 \pm 2$ & $15 \pm 2$ & $12 \pm 1$ & $16 \pm 3$ & $16 \pm 2$ & $18 \pm 4$ & $17 \pm 2$ \\
\hline & $\begin{array}{l}\text { NIPPV- } \\
\text { InSurE }\end{array}$ & $15 \pm 3$ & $12 \pm 2$ & $17 \pm 4$ & $15 \pm 3$ & $23 \pm 4^{\dagger}$ & $21 \pm 3^{\dagger}$ & $19 \pm 3$ & $26 \pm 6^{\dagger}$ & $28 \pm 7$ & $22 \pm 4$ \\
\hline
\end{tabular}

Values are expressed as mean \pm SEM.

NCPAP, nasal continuous positive airway pressure; NIPPV, nasal intermittent positive pressure ventilation: $O D$, oxygen delivery; $\mathrm{VO}_{2}$, oxygen consumption.

Statistical differences ${ }^{5} P<0.05$ vs. basal point; ${ }^{*} P<0.05$ vs. NCPAP group; and ${ }^{\dagger} P<0.05$ vs. NIPPV (one-way ANOVA); ${ }^{* * P}<0.05$ vs. NCPAP group and ${ }^{\ddagger} P<0.05$ vs. NIPPV group (two-way ANOVA). 
observed between groups in the numbers of BALs required. The procedure was well tolerated.

\section{Pulmonary Outcomes}

Gas exchange and lung mechanics. All animals had similar $\mathrm{pH}, P_{\mathrm{aCO} 2}, P_{\mathrm{aO} 2} / F_{\mathrm{iO} 2}$, and $C_{\mathrm{dyn}}$ parameters at baseline, after induction of SF-deficient lung injury and after $30 \mathrm{~min}$ of
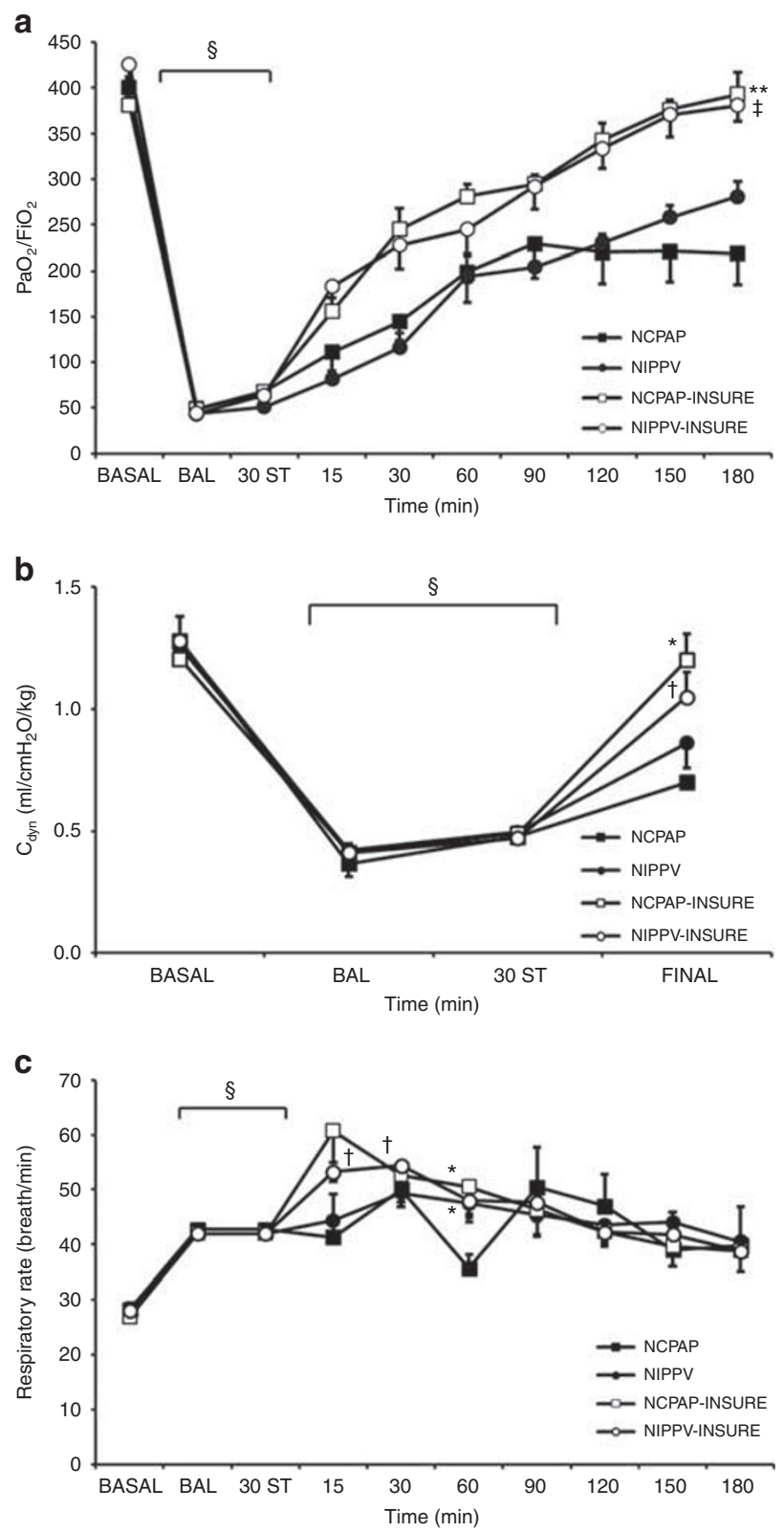

Figure 1. Changes in $P_{\mathrm{aO} 2} / F_{102}$ ratio, dynamic compliance $\left(C_{\mathrm{dyn}}\right)$, and respiratory rate in newborn piglets with surfactant-deficient lung injury treated with NIV (NCPAP or NIPPV) with or without surfactant treatment. $P_{\mathrm{aO} 2 /} F_{\mathrm{IO} 2}(\mathbf{a}), C_{\mathrm{dyn}}(\mathbf{b})$, and respiratory rate (c) values in the NCPAP (black square), NIPPV (black circle), NCPAP-Insure (white square), and NIPPVInsure (white circle) groups. ${ }^{\S} P<0.05$ vs. basal point; ${ }^{*} p<0.05$ versus NCPAP group; and ${ }^{\dagger} p<0.05$ versus NIPPV group (one-way ANOVA); ${ }^{*} P<0.05$ vs. NCPAP group; and ${ }^{\ddagger} P<0.05$ vs. NIPPV group (two-way ANOVA). Values are mean \pm SEM. BAL, bronchoalveolar lavage; ST, stabilization. stabilization (Table 1 and Figure 1). BAL produced an abrupt decrease in $P_{\mathrm{aO} 2} / F_{\mathrm{iO} 2}$ (Figure 1a), $C_{\mathrm{dyn}}$ (Figure 1b), and $\mathrm{pH}$ (Table 1), with a significant increase in the $P_{\mathrm{aCO} 2}$ level (Table 1). At baseline, after BAL and after $30 \mathrm{~min}$ of stabilization, there were no statistically significant differences between groups in any of the parameters studied.

$P_{\mathrm{aO} 2} / F_{\mathrm{iO} 2}$ ratio, $\mathrm{pH}$, and $\mathrm{P}_{\mathrm{aCO} 2}$ values showed a gradual improvement in NCPAP and NIPPV groups (Figure 1a and Table 1). Although respiratory rates were similar in the two NIV groups (Figure 1c), NIPPV showed hypercapnia throughout the study period, unlike the NCPAP group (Table 1).
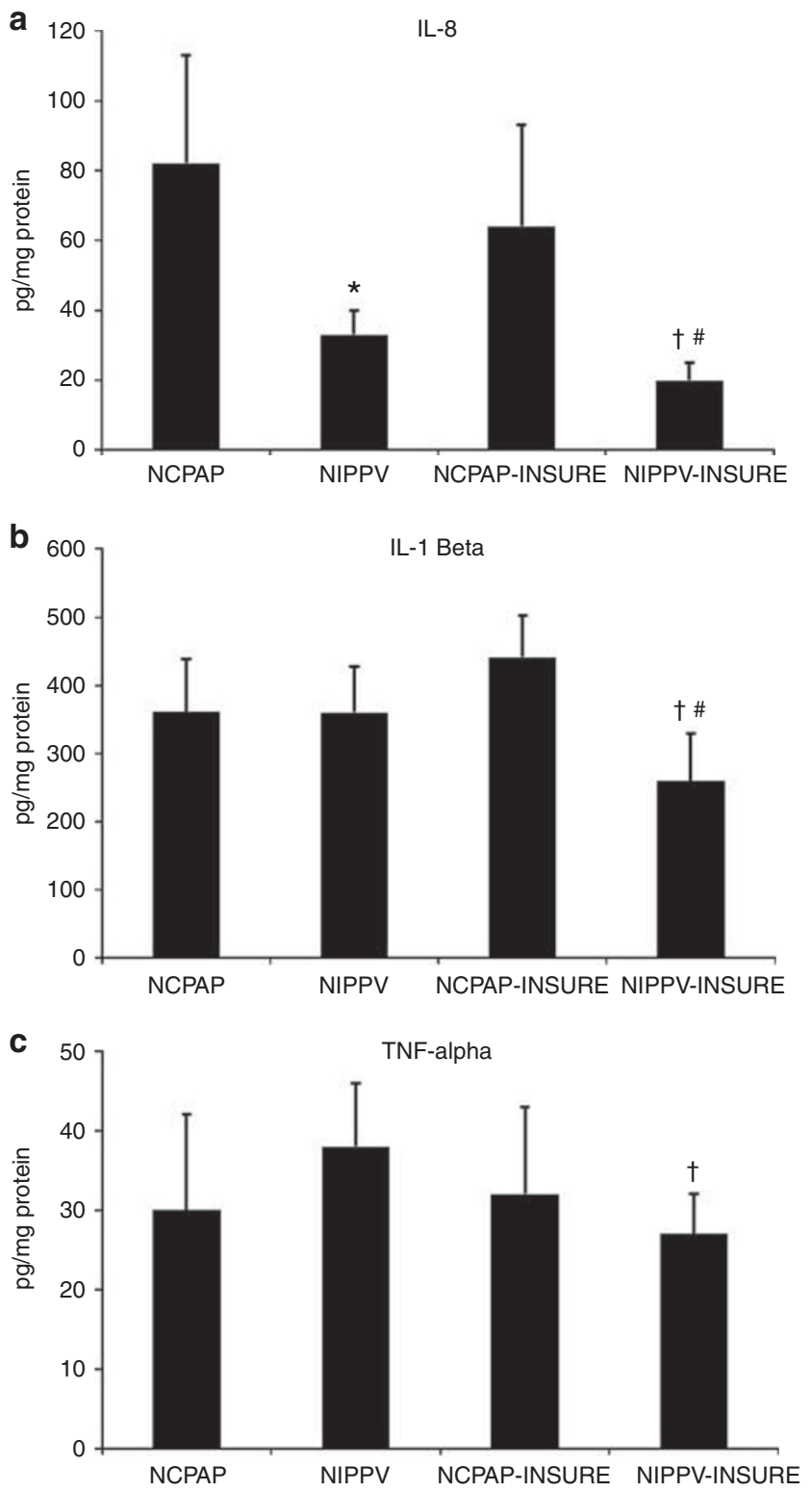

Figure 2. Lung inflammatory markers IL-8 (a), IL1- $\beta$ (b) and TNF- $\alpha$ (c) in surfactant-deficient newborn piglets treated with NIV (NCPAP or NIPPV), with or without surfactant treatment. ${ }^{*} P<0.05$ vs. NCPAP group; ${ }^{\dagger} P<0.05$ vs. NIPPV group; ${ }^{\#} P<0.05$ vs. NCPAP-Insure group were assessed using non-parametric Wilconson test. Values are mean \pm SEM. 


\section{Articles | Rey-Santano et al.}

The administration of SF and subsequent treatment with NCPAP or NIPPV produced a rapid improvement in $P_{\mathrm{aO} 2} / F_{\mathrm{iO} 2}$ ratio, $\mathrm{pH}$, and $P_{\mathrm{aCO} 2}$ compared with changes observed in animals not treated with SF (Figure 1a and Table 1). These improvements were maintained over time, and were similar in the two SF-treated groups.

Regarding $C_{\text {dyn }}$, although the SF-treated groups recovered to or close to the baseline values (100\% in the NCPAP-InSurE group and $85 \%$ in the NIPPV-InSurE group), only 60-65\% of $C_{\text {dyn }}$ recovery was observed with NCPAP or NIPPV alone (Figure 1b). No significant differences were observed between groups in tidal volume or resistance parameters (data not shown).

Lung inflammatory markers. Figure 2 shows the concentrations of the acute-phase cytokines IL-8, IL1- $\beta$, and tumor necrosis factor- $\alpha$ measured in lung homogenate. After $3 \mathrm{~h}$ of ventilation with NIPPV, IL- 8 levels were significantly lower than in the NCPAP group. Moreover, when SF was administered before NIPPV, lung inflammatory levels were observed to be lower. However, only a minimal difference could be seen between the two groups treated with NCPAP after $3 \mathrm{~h}$ of ventilation.
Lung injury. NIPPV-treated animals obtained lower lung injury scores than NCPAP animals, showing lower edema, alveolar hemorrhage, and interstitial hemorrhage values (Table 2 and Figure 3). SF administration was associated with less lung injury in the group treated with NCPAP, whereas differences in NIPPV groups with and without SF administration were not significant (Table 2 and Figure 3 ).

\section{Intrapulmonary Shunt and Oxygen Transport}

BAL produced an abrupt increase in $Q s / Q t$ values (Figure 4a), without significant changes in any of the systemic oxygen metabolism parameters (Table 1). NCPAP and NIPPV strategies were not associated with significant changes in oxygen delivery or $\mathrm{V}_{\mathrm{O} 2}$ (Table 1), whereas Qs/Qt gradually improved over time, although not reaching basal values (Figure 4a). When $\mathrm{SF}$ was administered, Qs/Qt recovered to baseline values in both SF-treated groups after $2 \mathrm{~h}$ of treatment (Figure 4a). Moreover, the combination of SF therapy with NIPPV ventilation was associated with a transient higher $V_{\mathrm{O} 2}$ values than NIPPV alone (Table 1).

\section{Hemodynamic Assessment}

At baseline, there were no differences between groups in the hemodynamic parameters studied. No significant changes in

Table 2. Total lung injury scores in surfactant-deficient newborn piglets treated with non-invasive ventilation (NCPAP or NIPPV) with or without surfactant treatment, using the Insure method

\begin{tabular}{|c|c|c|c|c|c|c|c|c|}
\hline $\begin{array}{l}\text { Lung } \\
\text { region }\end{array}$ & Groups & Atelectasis & Necrosis & Edema & $\begin{array}{c}\text { Alveolar } \\
\text { inflammation }\end{array}$ & $\begin{array}{c}\text { Interstitial } \\
\text { inflammation }\end{array}$ & $\begin{array}{c}\text { Alveolar } \\
\text { hemorrhage }\end{array}$ & $\begin{array}{c}\text { Interstitial } \\
\text { hemorrhage }\end{array}$ \\
\hline \multirow[t]{4}{*}{ Upper } & NCPAP & $1.00 \pm 0.71$ & 0 & $0.50 \pm 0.29$ & $0.50 \pm 0.50$ & $1.25 \pm 0.75$ & $1.00 \pm 0.41$ & $0.25 \pm 0.25$ \\
\hline & NIPPV & $0.33 \pm 0.21$ & 0 & 0 & $0.67 \pm 0.33$ & $1.33 \pm 0.42$ & $0^{*}$ & 0 \\
\hline & $\begin{array}{l}\text { NCPAP- } \\
\text { InSurE }\end{array}$ & $0.50 \pm 0.29$ & 0 & $0.25 \pm 0.25$ & $0.50 \pm 0.50$ & $1.25 \pm 0.25$ & $0.25 \pm 0.25$ & $0.25 \pm 0.25$ \\
\hline & $\begin{array}{l}\text { NIPPV- } \\
\text { InSurE }\end{array}$ & $1.40 \pm 0.24$ & 0 & $0.20 \pm 0.20$ & $0.80 \pm 0.37$ & $1.80 \pm 0.45$ & 0 & $0.20 \pm 0.20$ \\
\hline \multirow[t]{4}{*}{ Middle } & NCPAP & $1.25 \pm 0.63$ & 0 & $1.00 \pm 0.71$ & $0.75 \pm 0.48$ & $1.5 \pm 0.87$ & $1.00 \pm 0.58$ & $0.25 \pm 0.25$ \\
\hline & NIPPV & $0.67 \pm 0.33$ & 0 & 0 & $0.50 \pm 0.34$ & $1.0 \pm 0.26$ & 0 & 0 \\
\hline & $\begin{array}{l}\text { NCPAP- } \\
\text { InSurE }\end{array}$ & $0.25 \pm 0.25$ & 0 & 0 & $0.75 \pm 0.48$ & $1.00 \pm 0.41$ & $0^{*}$ & $0.25 \pm 0.25$ \\
\hline & $\begin{array}{l}\text { NIPPV- } \\
\text { InSurE }\end{array}$ & $1.00 \pm 0.32$ & 0 & $0.20 \pm 0.20$ & $1.20 \pm 0.58$ & $1.60 \pm 0.51$ & $0.20 \pm 0.20$ & $0.20 \pm 0.20$ \\
\hline \multirow[t]{4}{*}{ Lower } & NCPAP & $1.75 \pm 0.63$ & 0 & $0.75 \pm 0.25$ & $0.50 \pm 0.50$ & $1.75 \pm 0.75$ & $1.00 \pm 0.58$ & $0.25 \pm 0.25$ \\
\hline & NIPPV & $1.17 \pm 0.40$ & 0 & $0 *$ & $0.83 \pm 0.31$ & $1.50 \pm 0.43$ & 0 & 0 \\
\hline & $\begin{array}{l}\text { NCPAP- } \\
\text { InSurE }\end{array}$ & $0.25 \pm 0.25$ & 0 & $0^{*}$ & $0.75 \pm 0.25$ & $1.25 \pm 0.63$ & $0^{*}$ & $0.5 \pm 0.29$ \\
\hline & $\begin{array}{l}\text { NIPPV- } \\
\text { InSurE }\end{array}$ & $0.80 \pm 0.37$ & 0 & $0.22 \pm 0.22$ & $1.00 \pm 0.44$ & $1.00 \pm 0.32$ & 0 & $0.20 \pm 0.20$ \\
\hline \multirow[t]{4}{*}{ Total } & NCPAP & $1.33 \pm 0.36$ & 0 & $0.75 \pm 0.25$ & $0.58 \pm 0.26$ & $1.50 \pm 0.42$ & $1.00 \pm 0.28$ & $0.25 \pm 0.13$ \\
\hline & NIPPV & $0.72 \pm 0.19$ & 0 & $0^{*}$ & $0.66 \pm 0.18$ & $1.28 \pm 0.21$ & $0^{*}$ & $0^{*}$ \\
\hline & $\begin{array}{l}\text { NCPAP- } \\
\text { InSurE }\end{array}$ & $0.33 \pm 0.14^{*}$ & 0 & $0.08 \pm 0.08^{*}$ & $0.67 \pm 0.22$ & $1.17 \pm 0.24$ & $0.08 \pm 0.08 *$ & $0.33 \pm 0.14$ \\
\hline & $\begin{array}{l}\text { NIPPV- } \\
\text { InSurE }\end{array}$ & $1.06 \pm 0.18$ & 0 & $0.20 \pm 0.10$ & $1.00 \pm 0.25$ & $1.47 \pm 0.21$ & $0.06 \pm 0.06$ & $0.20 \pm 0.11$ \\
\hline
\end{tabular}

Statistical differences were assessed using Wilcoxon non-parametric test. Values are expressed as mean \pm SEM. NCPAP, nasal continuous positive airway pressure; NIPPV, nasal intermittent positive pressure ventilation.

${ }^{*} P<0.05$ vs. NCPAP group. 


\section{NIV and surfactant for RDS treatment Articles}

MABP were observed after BAL (Figure $4 \mathbf{b}$ ), while the HR rose (Figure 4c). During the study period, MABP was higher in animals under NIPPV than those under NCPAP. On the other hand, SF administration together with NCPAP ventilation maintained a higher MABP than observed in the NCPAP group, without any significant differences in HR.

\section{Cerebral Evaluation}

Carotid blood flow increased in all groups after the BAL procedure (Figure 4d). NIV strategies with or without SF administration produced a continuous decrease in carotid blood flow, this reaching baseline values after 90 min under NCPAP and NIPPV alone, and after $30 \mathrm{~min}$ in both groups treated with SF (Figure 4d).

All groups studied showed low brain injury scores, with similar hemorrhage, inflammation, and infarction scores in all regions studied (Table 3 and Figure 5). Nevertheless, brain necrosis and edema scores were lower in animals that received NIPPV treatment, and in the group treated with SF and NCPAP, than those under NCPAP alone.

\section{DISCUSSION}

We have been able to demonstrate in our spontaneously breathing newborn piglet model of SF-deficient lung injury that two different modes of NIV (NCPAP and NIPPV) are both associated with gradual improvements in pulmonary status. NIPPV shows similar pulmonary outcomes, but with lower lung histological score and inflammatory marker level than NCPAP. Moreover, when SF replacement therapy is administered, using the InSurE method, with NIV, more rapid and significant improvements in pulmonary outcomes are observed than with the same mode of NIV without SF administration. In addition, our results suggest that SF administration improves lung injury score when it is administered with NCPAP. The administration of SF with NIPPV is able to achieve even lower levels of lung inflammation markers than those observed after treatment with NIPPV alone; however, the lung injury score was not significantly lower. Both methods of NIV with SF delivery are effective therapies and neither was observed to produce significant changes in the brain.

\section{Evaluation of NIV Strategies: NCPAP vs. NIPPV}

NCPAP has been widely used in neonatal critical care units as a standard mode of NIV since it was first introduced in 1971 (ref. 1). NIPPV is considered to be a strengthened version of NCPAP, which helps by increasing lung volumes, facilitates gas exchange, and initiates inspiratory reflexes and thereby respiratory drive (2).

In our SF-depleted animals, we observed that NIPPV produced similar pulmonary outcomes (oxygenation, respiratory rate, and lung mechanics), but less lung inflammation and lower lung injury scores than in the NCPAP group, at $3 \mathrm{~h}$ of follow-up. On the other hand, our animals treated with NIPPV developed hypercarbia. This might be attributable to the fact that it was found difficult to achieve optimal synchronization between the ventilator and the piglets' triggered breaths during the first few minutes of NIPPV; in
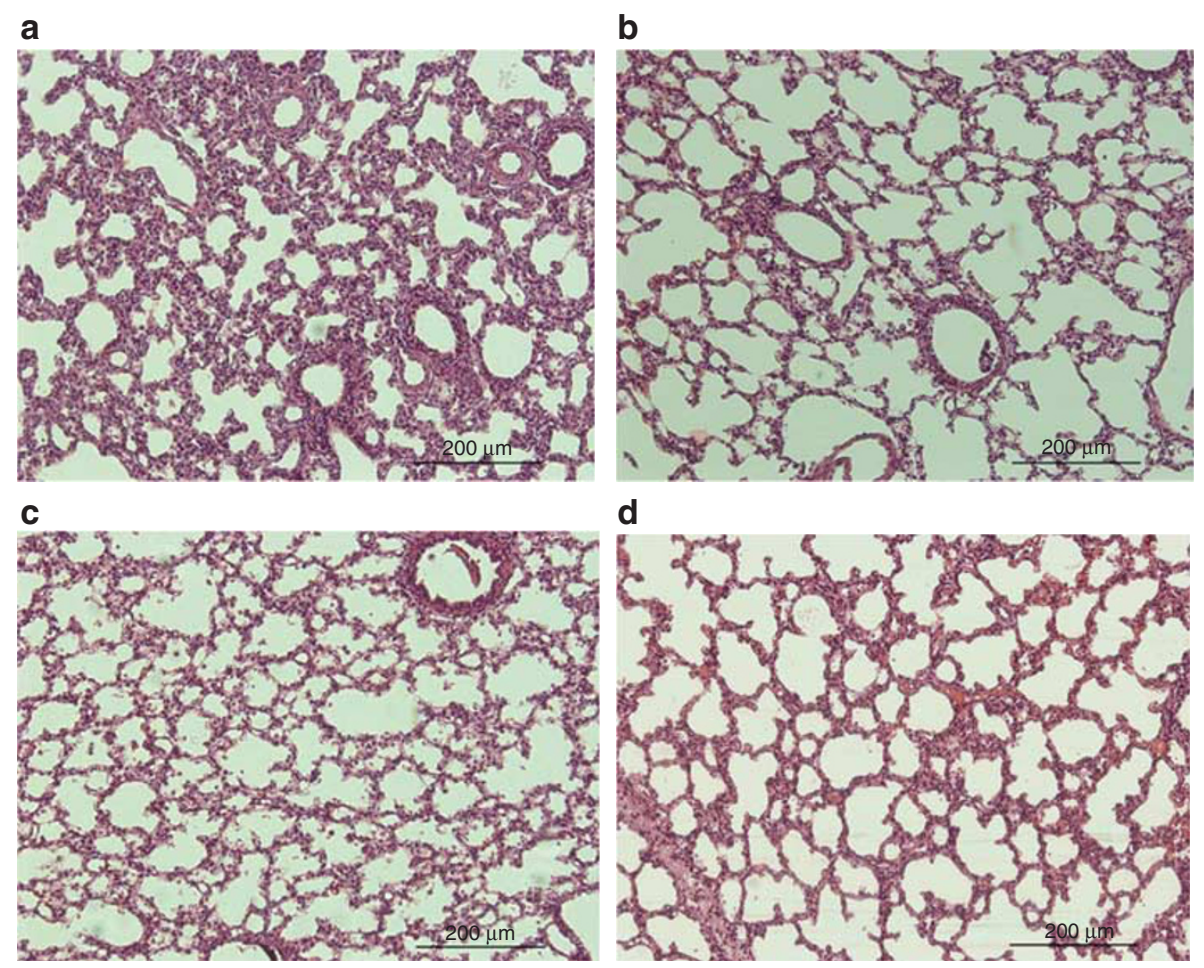

Figure 3. Photomicrographs ( $\times 200$ magnification) of representative lung sections from NCPAP (a), NIPPV (b), NCPAP-Insure (c), and NIPPV-Insure (d) groups. Panels were obtained from the middle region of the lung. 

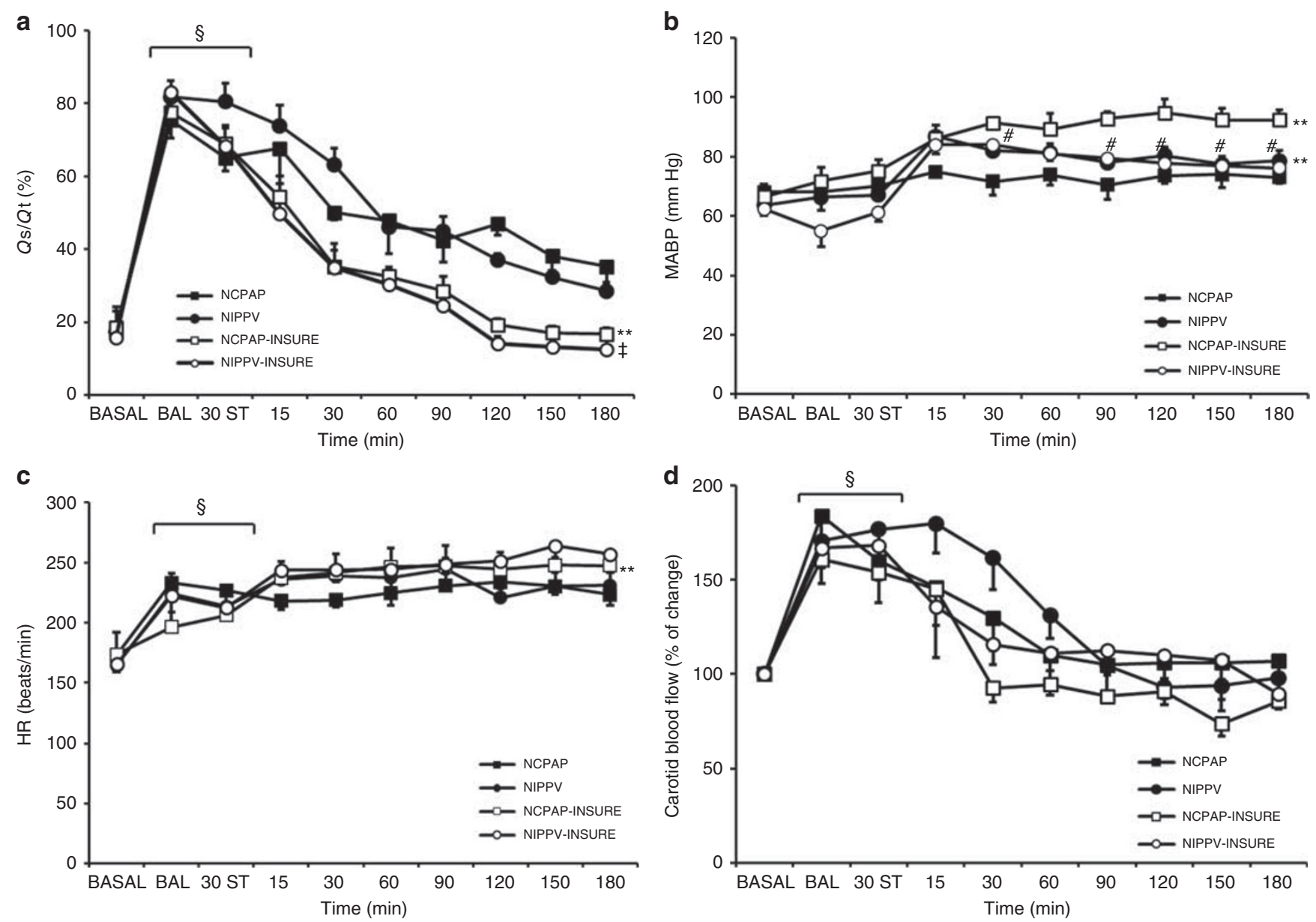

Figure 4. Changes in intrapulmonary shunt (Qs/Qt), arterial blood pressure (MABP), heart rate (HR), and carotid blood flow (d) in newborn piglets with surfactant-deficient lung injury treated with NIV (NCPAP or NIPPV), with or without surfactant treatment. Mean Qs/Qt (a) MABP (b), mean HR (c), and mean carotid blood flow (d) values in the NCPAP (black square), NIPPV (black circle), NCPAP-Insure (white square), and NIPPV-Insure (white circle) groups. ${ }^{\S} P<0.05$ vs. basal point; ${ }^{\#} P<0.05$ vs. NCPAP-Insure group (one-way ANOVA); ${ }^{* *} P<0.05$ vs. NCPAP group and ${ }^{\ddagger} P<0.05$ vs. NIPPV group (two-way ANOVA). Values are mean \pm SEM. BAL, bronchoalveolar lavage; ST, stabilization.

turn, this would have resulted in inadequate respiratory muscle rest, gas exchange, and patient discomfort; these factors make it difficult to achieve a tidal volume adequate to achieve rapid $\mathrm{CO}_{2}$ removal, although the problem resolved over the course of the experimental period.

Previously, it has been demonstrated that the initial acute pulmonary inflammatory response to mechanical ventilation induces a complex process, eventually leading to irreversible lung damage and fibrosis (20). Among others, proinflammatory cytokines such as IL-1B and IL- 6 and chemoattractant proteins such as IL- 8 were found to be elevated early in the BAL fluid of infants developing BPD (21). In order to avoid the harmful effects of mechanical ventilation, NCPAP and NIPPV have been widely used as way of providing NIV in neonatal units $(1,2)$. In line with our results, preclinical studies demonstrated that NIPPV improved ventilation and tended to be associated with less lung inflammation than observed with intubated mechanical ventilation in SFdeficient term piglets (12), whereas NCPAP was not associated with lower levels of lung markers of inflammation than those in mechanically ventilated preterm lambs (22). The exact mechanisms of the reduction of inflammatory responses during NIPPV cannot yet be elucidated through our experimental approach. Although the difference observed did not reach significance, oxygenation and dynamic compliance tended to be better in the NPPV group than the NCPAP at the end of the experiment, and, hence, it could be hypothesized that the former might result in less mechanical trauma. It is unclear whether the aforementioned advantages provided by NIPPV are due to the pressure changes, or simply by the provision of a higher mean airway pressure than with NCPAP (23).

Some clinical trials have suggested that NIPPV may be advantageous over NCPAP as primary support; however, the evidence is not conclusive (4-9). Several authors have reported less need for endotracheal ventilation, less risk of intubation in the first $72 \mathrm{~h}$ after birth, lower incidence of bronchopulmonary dysplasia, and less frequent apnea $(4,24)$. However, a recent large multicenter trial (9) detected no significant differences in terms of mortality or 


\section{NIV and surfactant for RDS treatment Articles}

Table 3. Total brain injury scores in surfactant-deficient newborn piglets treated with non-invasive ventilation (NCPAP or NIPPV) with or without surfactant treatment, using the Insure method

\begin{tabular}{|c|c|c|c|c|c|}
\hline & Necrosis & Edema & Inflammation & Hemorrhage & Infarct \\
\hline \multicolumn{6}{|l|}{ Cortex } \\
\hline NCPAP & $14(9-20)$ & $0.9(0-2)$ & $0.5(0-2)$ & $0(0-0)$ & $0(0-0)$ \\
\hline NIPPV & $10(4-16)^{*}$ & $0.6(0-1)$ & $0.4(0-1)$ & $0(0-0)$ & $0(0-0)$ \\
\hline NCPAP-InSurE & $12(6-18)$ & $0.8(0-1)$ & $0.6(0-1)$ & $0(0-0)$ & $0(0-0)$ \\
\hline NIPPV-InSurE & $7(2-13)^{\dagger, \#}$ & $0.5(0-1)^{\#}$ & $0.4(0-1)$ & $0(0-0)$ & $0(0-0)$ \\
\hline \multicolumn{6}{|l|}{ Inner } \\
\hline NCPAP & $13(8-20)$ & $0.7(0-2)$ & $0.4(0-1)$ & $0(0-0)$ & $0(0-0)$ \\
\hline NIPPV & $7(0-14)^{*}$ & $0.4(0-1)$ & $0.3(0-1)$ & $0(0-0)$ & $0(0-0)$ \\
\hline NCPAP-InSurE & $8(2-13)^{*}$ & $0.5(0-1)$ & $0.5(0-1)$ & $0(0-0)$ & $0(0-0)$ \\
\hline NIPPV-InSurE & $10(3-16)$ & $0.5(0-1)$ & $0.4(0-1)$ & $0(0-0)$ & $0(0-0)$ \\
\hline \multicolumn{6}{|l|}{$C B+B$} \\
\hline NCPAP & $11(2-18)$ & $0.5(0-1)$ & $0.3(0-1)$ & $0(0-0)$ & $0(0-0)$ \\
\hline NIPPV & $6(0-15)$ & $0.1(0-1)^{*}$ & $0.1(0-1)$ & $0(0-0)$ & $0(0-0)$ \\
\hline NCPAP-InSurE & $8(1-14)$ & $0(0-0)^{*}$ & $0(0-0)$ & $0(0-0)$ & $0(0-0)$ \\
\hline NIPPV-InSurE & $6(1-16)$ & $0(0-0)$ & $0(0-0)$ & $0(0-0)$ & $0(0-0)$ \\
\hline \multicolumn{6}{|l|}{ Total } \\
\hline NCPAP & $13(2-20)$ & $0.7(0-2)$ & $0.4(0-2)$ & $0(0-0)$ & $0(0-0)$ \\
\hline NIPPV & $8(0-16)^{*}$ & $0.4(0-1)^{*}$ & $0.3(0-1)$ & $0(0-0)$ & $0(0-0)$ \\
\hline NCPAP-InSurE & $10(1-18)^{*}$ & $0.5(0-1)$ & $0.4(0-1)$ & $0(0-0)$ & $0(0-0)$ \\
\hline NIPPV-InSurE & $8(2-16)$ & $0.4(0-1)$ & $0.3(0-1)$ & $0(0-0)$ & $0(0-0)$ \\
\hline
\end{tabular}

Statistical differences were assessed using Wilcoxon non-parametric test. Values are expressed as mean \pm range.

$\mathrm{CB}+\mathrm{B}$, cerebellum+brainstem; NCPAP, nasal continuous positive airway pressure; NIPPV, nasal intermittent positive pressure ventilation.

${ }^{*} P<0.05$ vs. NCPAP group; ${ }^{\dagger} P<0.05$ vs. NIPPV group; ${ }^{*} P<0.05$ vs. NCPAP-InSurE group.

bronchopulmonary dysplasia,; however, differences in study methodology between participating centers mean that these findings should be interpreted with caution (25).

\section{Evaluation of NIV Strategies Combined with SF Treatment}

In a relatively large number of infants NIV has enabled mechanical ventilation to be avoided; nevertheless, it remains relatively frequent for many infants to require endotracheal ventilation and SF administration (26). Intratracheal SF replacement therapy has been the mainstay of treatment for preterm infants with RDS for more than 20 years. In recent years, clinicians are increasingly attempting rapid extubation of preterm infants following SF therapy (InSurE method) (16) or advancing a thin tube through the vocal cords (27), in order to decrease the risk of barotrauma and/or volutrauma, and ultimately decrease the incidence of bronchopulmonary dysplasia.

Early SF administration plays a critical role in reducing the need for invasive ventilation, but only a few clinical studies $(5,7,28,29)$ have evaluated the effects of SF therapy with NIV (NIPPV or NCPAP). Those studies have suggested that
NIPPV and early SF administration may have a synergistic effect in showing lower failure of nasal support (29), and decreasing bronchopulmonary dysplasia secondary to minimizing mechanical ventilation during the transitional period, when the lung of preterm infants may be more susceptible to volutrauma or oxygen-related lung inflammation (30). In accordance with this assumption, our study demonstrates that pulmonary outcomes rapidly improve after SF administration, when it is followed by NIV. Moreover, our study suggests that SF therapy administered before NCPAP may be necessary to provide adequate pulmonary injury protection, as previously reported (11), whereas SF administration before NIPPV appears to be an essential factor for providing an extra antiinflammatory effect.

SF administration modulates the pulmonary inflammatory cascade, inhibiting oxidative burst activity, and stimulates endogenous SF synthesis (31). Moreover, natural SFs have been described to have anti-inflammatory properties because of their high content of plasmalogens, phospholipids, and SF proteins, among other elements (32). Hence, it is plausible that the combination of gentle ventilation with SF treatment 


\section{Articles | Rey-Santano et al.}
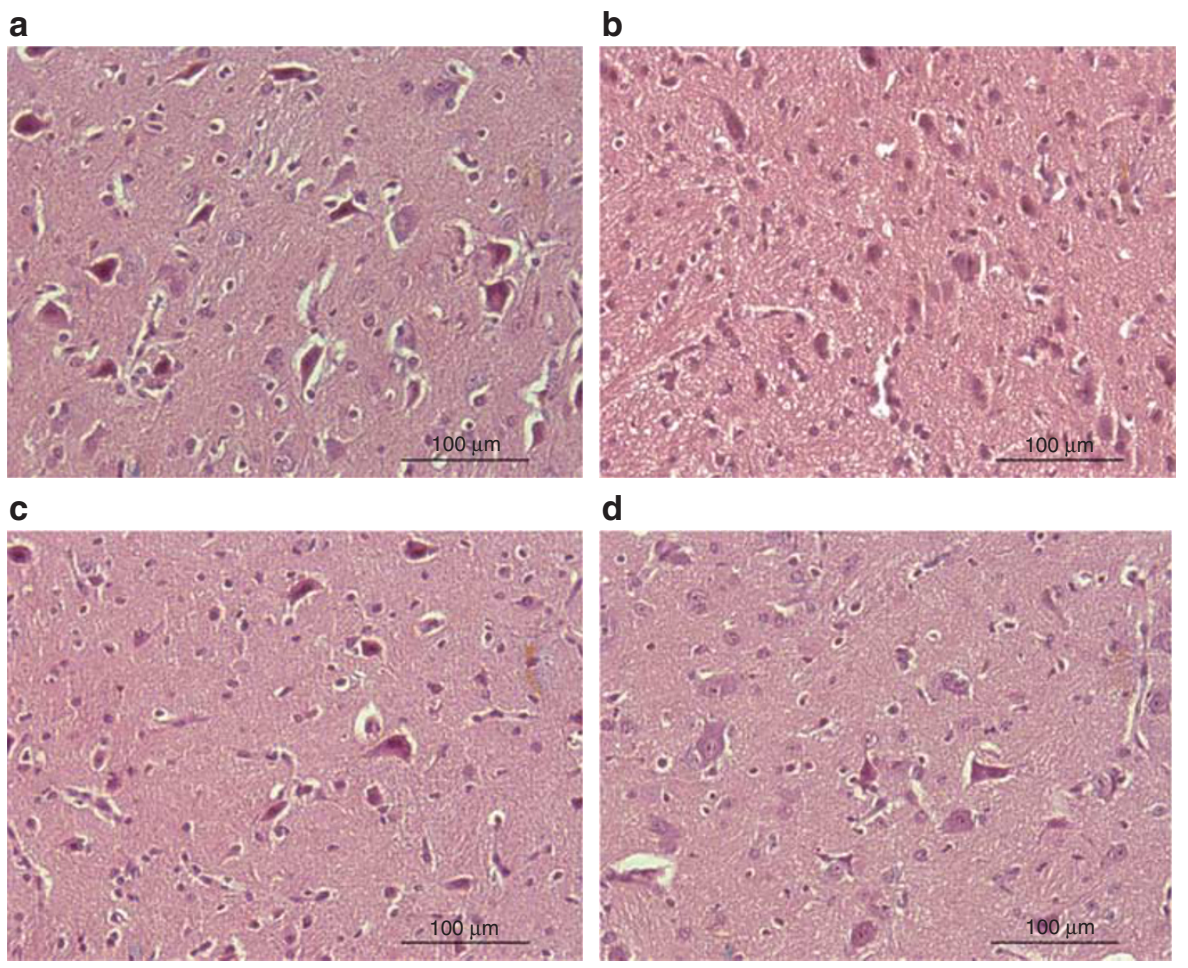

Figure 5. Photomicrographs ( $\times 200$ magnification) of representative brain sections from NCPAP (a), NIPPV (b), NCPAP-Insure (c), and NIPPV-Insure (d) groups. Panels were obtained from the striatum region of the brain.

may minimize the initiation and progression of lung inflammation, as observed in our study when SF is administered before NIPPV.

Taken together, our findings support the view that SF confers a protective effect against pulmonary inflammation (32) as well as has a potential to reduce injury (33), depending on the NIV used.

Another important consideration is the effect of respiratory support at birth on other organ systems, especially the brain, and this remains relatively unexplored. It is of particular importance, given that preterm infants have a significantly higher risk of acute and chronic brain injury than term infants (34). There is increasing evidence from animal studies that ventilation-induced lung injury leads to systemic brain inflammation and injury, due to hemodynamic instability and a localized cerebral inflammatory response (35). In our study, neither of the NIV strategies with or without SF therapy was observed to have any significant clinical effects on systemic oxygen metabolism, hemodynamic parameters, carotid blood flow, or brain injury score, confirming the safety of these NIV modalities (36).

\section{Limitations}

Limitations of this study include the use of newborn piglets (2-4-day old) instead of premature animals. The intubated premature lamb has been the gold-standard animal model to study the pathogenesis and the treatments of neonatal RDS for many decades; nevertheless, the use of non-invasive support such NCPAP or NIPPV using premature lambs remains complicated, and the pulmonary outcomes after SF treatment in combination with NIV are difficult to interpret because of the high variability in the response to NIV and SF (37). Moreover, fetal lamb cerebral development is quite advanced compared with that in human fetuses (38). On the other hand, a premature piglet model may be a good animal model for studying preterm neonatal pathologies because of many aspects of their organ development (brain, lung, etc.) being similar to that in the premature infant (39). Nevertheless, technical problems associated with the management of an animal as large as a pregnant sow $(280-350 \mathrm{~kg})$ and the large numbers of expert staff and quantity of intensive care equipment required for dealing with the resuscitation and initiation of NIV for the large number of piglets at preterm cesarean section make this animal model not feasible for many researchers.

SF washout lavage model has been frequently used in adult and juvenile animals to implement successful animal models of acute pulmonary failure in the context of RDS (11-14). The newborn piglet model was chosen because the brain maturation, lung volume, and birth weights resemble those of newborn infants. Moreover, the feasibility of using NIV strategies in this model of SF-deficient lung injury has been previously demonstrated $(11,12,15)$. However, 2 - to 4 -day-old piglets have a brain development higher than 32-week human fetus (39). NIV effects on the brain need to be interpreted with caution as effects on term-piglet brain may not be the same as those on the vulnerable premature brain of newborn infants. 


\section{NIV and surfactant for RDS treatment 1 Articles}

Another limitation may be the length of treatment that was relatively short. However, indicators of lung injury have been shown to be measurable within $2 \mathrm{~h}$ of preterm birth (40). We chose to treat animals for $3 \mathrm{~h}$ to optimize the potential response of early inflammatory markers, while still modeling a period of short-term ventilatory support. Our data indicate that the length of the study was adequate to detect early lung markers of inflammation, with significant differences noted between SF-treated and non-treated animals.

\section{CONCLUSION}

In spontaneously breathing SF-deficient newborn piglets, NIPPV is a suitable NIV strategy potentially associated with less lung inflammation markers and lung injury than NCPAP. Moreover, SF administration provides protection against ventilatory damage in both NIV strategies; however, the degree of pulmonary benefit is related to the NIV strategy used. None of treatments studied seem to have a negative impact on the neonatal brain.

\section{STATEMENT OF FINANCIAL SUPPORT}

This study has been funded by Instituto de Salud Carlos III through the project FIS 14/024 (Co-financed by the European Regional Development Fund/European Social Fund- "Investing in your future") and Chiesi Farmaceutici.

Disclosure: Francesca Ricci, Federico Bianco, and Fabrizio Salomone are employees at Chiesi Farmaceuti (manufacturer of poractant alfa sold under the brand name). The remaining authors declare no conflict of interest.

\section{REFERENCES}

1. Gregory GA, Kitterman JA, Phibbs RH, et al. Treatment of the idiopathic respiratory distress syndrome with continuous positive airway pressure. N Engl J Med 1971;284:1333-40.

2. Bhandari V. Nasal intermittent positive pressure ventilation in the newborn: review of literature and evidence-based guidelines. J Perinatol 2010;30:505-12.

3. Aghai ZH, Saslow JG, Nakhla T, et al. Synchronized nasal intermittent positive pressure ventilation (SNIPPV) decreases work of breathing (WOB) in premature infants with respiratory distress syndrome (RDS) compared to nasal continuous positive airway pressure (NCPAP). Pediatr Pulmonol 2006;41:875-1.

4. Kugelman A, Feferkorn I, Riskin A, et al. Nasal intermittent mandatory ventilation versus nasal continuous positive airway pressure for respiratory distress syndrome: a randomized, controlled, prospective study. J Pediatr 2007;150:521-6 e521.

5. Sai Sunil Kishore M, Dutta S, Kumar P. Early nasal intermittent positive pressure ventilation versus continuous positive airway pressure for respiratory distress syndrome. Acta Paediatr 2009;98:1412-5.

6. Bisceglia M, Belcastro A, Poerio V, et al. A comparison of nasal intermittent versus continuous positive pressure delivery for the treatment of moderate respiratory syndrome in preterm infants. Minerva Pediatr 2007;59:91-5.

7. Meneses J, Bhandari V, Alves JG, Herrmann D. Noninvasive ventilation for respiratory distress syndrome: a randomized controlled trial. Pediatrics 2011;127:300-7.

8. Shi Y, Tang S, Zhao J, Shen J. A prospective, randomized, controlled study of NIPPV versus nCPAP in preterm and term infants with respiratory distress syndrome. Pediatr Pulmonol 2014;49:673-8.

9. Kirpalani H, Millar D, Lemyre B, et al. A trial comparing noninvasive ventilation strategies in preterm infants. N Engl J Med 2013;369:611-20.

10. Ramanathan R. Nasal respiratory support through the nares: its time has come. J Perinatol 2010;30 (Suppl): S67-72.
11. Nold JL, Meyers PA, Worwa CT, et al. Decreased lung injury after surfactant in piglets treated with continuous positive airway pressure or synchronized intermittent mandatory ventilation. Neonatology 2007;92:19-25.

12. Lampland AL, Meyers PA, Worwa CT, et al. Gas exchange and lung inflammation using nasal intermittent positive-pressure ventilation versus synchronized intermittent mandatory ventilation in piglets with saline lavage-induced lung injury: an observational study. Crit Care Med 2008;36:183-7.

13. Ricci F, Catozzi C, Murgia X, et al. Physiological, biochemical, and biophysical characterization of the lung-lavaged spontaneously-breathing rabbit as a model for respiratory distress syndrome. PLoS ONE 2017;12:e0169190.

14. Lachmann B, Robertson B, Vogel J. In vivo lung lavage as an experimental model of the respiratory distress syndrome. Acta Anaesthesiol Scand 1980;24:231-6.

15. von der Hardt K, Schoof E, Kandler MA, et al. Aerosolized perfluorocarbon suppresses early pulmonary inflammatory response in a surfactant-depleted piglet model. Pediatr Res 2002;51:177-82.

16. Verder H, Robertson B, Greisen G, et al. Surfactant therapy and nasal continuous positive airway pressure for newborns with respiratory distress syndrome. Danish-Swedish Multicenter Study Group. N Engl J Med 1994:331:1051-5.

17. Bradford MM. A rapid and sensitive method for the quantitation of microgram quantities of protein utilizing the principle of protein-dye binding. Anal Biochem 1976;72:248-54.

18. Zimmermann AM, Roberts $\mathrm{KD}$, Lampland $\mathrm{AL}$, et al. Improved gas exchange and survival after KL-4 surfactant in newborn pigs with severe acute lung injury. Pediatr Pulmonol 2010;45:782-8.

19. Rey-Santano C, Mielgo VE, López-de-Heredia-Y-Goya J, et al. Cerebral effect of intratracheal aerosolized surfactant versus bolus therapy in preterm lambs. Crit Care Med 2016;44:e218-26.

20. Naik AS, Kallapur SG, Bachurski CJ, et al. Effects of ventilation with different positive end-expiratory pressures on cytokine expression in the preterm lamb lung. Am J Respir Crit Care Med 2001;164:494-8.

21. Ozdemir A, Brown MA, Morgan WJ. Markers and mediators of inflammation in neonatal lung disease. Pediatr Pulmonol 1997;23:292-306.

22. Polglase GR, Hillman NH, Ball $\mathrm{MK}$, et al. Lung and systemic inflammation in preterm lambs on continuous positive airway pressure or conventional ventilation. Pediatr Res 2009;65:67-71.

23. Owen LS, Morley CJ, Davis PG. Pressure variation during ventilator generated nasal intermittent positive pressure ventilation in preterm infants. Arch Dis Child Fetal Neonatal Ed 2010;95:F359-64.

24. Lemyre B, Davis PG, de Paoli AG. Nasal intermittent positive pressure ventilation (NIPPV) versus nasal continuous positive airway pressure (NCPAP) for apnea of prematurity. Cochrane Database Syst Rev 2002: CD002272.

25. Roberts CT, Davis PG, Owen LS. Neonatal non-invasive respiratory support: synchronised NIPPV, non-synchronised NIPPV or bi-level CPAP: what is the evidence in 2013? Neonatology 2013;104:203-9.

26. Stefanescu BM, Murphy WP, Hansell BJ, et al. A randomized, controlled trial comparing two different continuous positive airway pressure systems for the successful extubation of extremely low birth weight infants. Pediatrics 2003;112:1031-8.

27. Dargaville PA, Aiyappan A, De Paoli AG, et al. Minimally-invasive surfactant therapy in preterm infants on continuous positive airway pressure. Arch Dis Child Fetal Neonatal Ed 2013;98:F122-6.

28. Bhandari V, Gavino RG, Nedrelow JH, et al. A randomized controlled trial of synchronized nasal intermittent positive pressure ventilation in RDS. J Perinatol 2007;27:697-703.

29. Duman N, Tüzün F, Sever AH, et al. Nasal intermittent positive pressure ventilation with or without very early surfactant therapy for the primary treatment of respiratory distress syndrome. J Matern Fetal Neonatal Med 2016;29:252-7.

30. Ramanathan R, Sekar KC, Rasmussen M, et al. Nasal intermittent positive pressure ventilation after surfactant treatment for respiratory distress syndrome in preterm infants $<30$ weeks' gestation: a randomized, controlled trial. J Perinatol 2012;32:336-43. 


\section{Articles | Rey-Santano et al.}

31. Bunt JE, Carnielli VP, Janssen DJ, et al. Treatment with exogenous surfactant stimulates endogenous surfactant synthesis in premature infants with respiratory distress syndrome. Crit Care Med 2000;28:3383-8.

32. Ikegami M, Whitsett JA, Martis PC, Weaver TE. Reversibility of lung inflammation caused by SP-B deficiency. Am J Physiol Lung Cell Mol Physiol 2005;289:L962-70.

33. Krause MF, Wiemann T, Reisner A, et al. Surfactant reduces extravascular lung water and invasion of polymorphonuclear leukocytes into the lung in a piglet model of airway lavage. Pulm Pharmacol Ther 2005;18:129-39.

34. Beck S, Wojdyla D, Say L, et al. The worldwide incidence of preterm birth: a systematic review of maternal mortality and morbidity. Bull World Health Organ 2010;88:31-8.

35. Polglase GR, Miller SL, Barton SK, et al. Initiation of resuscitation with high tidal volumes causes cerebral hemodynamic disturbance, brain inflammation and injury in preterm lambs. PLoS ONE 2012;7:e39535.
36. Dani C, Bertini G, Cecchi A, et al. Brain haemodynamic effects of nasal continuous airway pressure in preterm infants of less than 30 weeks' gestation. Acta Paediatr 2007;96:1421-5.

37. Hütten MC, Kuypers E, Ophelders DR, et al. Nebulization of Poractant alfa via a vibrating membrane nebulizer in spontaneously breathing preterm lambs with binasal continuous positive pressure ventilation. Pediatr Res 2015;78:664-9.

38. Yager JY, Ashwal S. Animal models of perinatal hypoxic-ischemic brain damage. Pediatr Neurol 2009;40:156-67.

39. Eiby YA, Wright LL, Kalanjati VP, et al. A pig model of the preterm neonate: anthropometric and physiological characteristics. PLoS ONE 2013;8:e68763.

40. Jobe AH, Kramer BW, Moss TJ, et al. Decreased indicators of lung injury with continuous positive expiratory pressure in preterm lambs. Pediatr Res 2002;52:387-92. 